\title{
Lean production as a means of ensuring the sustainable development of agricultural enterprises
}

\author{
Tetiana Ostapchuk ${ }^{1}$, Nataliia Valinkevych ${ }^{1}$, Hanna Tkachuk $^{1}$, Kateryna Orlova ${ }^{1, *}$, and Tetiana Melnyk ${ }^{2}$ \\ ${ }^{1}$ Zhytomyr Polytechnic State University, Department of Management and Entrepreneurship, 103 Chudnivska Str., Zhytomyr, 10005, \\ Ukraine \\ ${ }^{2}$ Zhytomyr Polytechnic State University, Department of Digital Economics and International Economic Relations, 103 Chudnivska Str., \\ Zhytomyr, 10005, Ukraine
}

\begin{abstract}
The article considers the theoretical essence of the lean production concept. It has been proved that its essence lies in identifying and reducing costs of processes, and sometimes eliminating business processes that do not create added value but consume large amount of resources. The main constituent elements, tools and principles of lean concept implementation have been outlined. The possibility of implementation of lean logistics in the activity of agricultural enterprises has been considered. It has been defined that combination of lean logistics and "green logistics" is a rational way to increase both economic and ecological efficiency. The VSM tool have been offered for implementation of the lean concept. VSM maps provide a visual representation of step-by-step scenario to achieve the strategic goals of the company, representing material and information flows required to deliver a product to the final consumer. It has been confirmed that the implementation of the lean concept at agricultural enterprises is an element of ensuring their functioning on the basis of sustainable development, a means of increasing environmental and economic efficiency.
\end{abstract}

\section{Introduction}

Exacerbation of crisis tendencies in the socio-economic sphere, increase of competition for resources, understanding of their exhaustiveness and the need for efficient and rational use, deterioration of the natural environment place particular emphasis on ensuring the sustainable development of the economy as a whole as well as of its individual industries.

Sustainable development as a concept of social and economic development involves balanced and stable functioning of economic entities with ensuring minimum of harmful impact on natural environment. Sustainable development contributes to the following:

- efficient functioning of the economic entities;

- balanced use of natural resources and reduce of the anthropogenic burden on natural environment:

- ensuring the society well-being through the supply of safe food products and providing normal living conditions.

Taking into account the mentioned above, sustainable development ensuring is extremely important under modern conditions.

Ensuring sustainable development is especially important for agricultural enterprises, as agricultural production not only shapes the food security of the country, but also acts as a direct user of natural resources. Therefore, management of the agricultural enterprises' activities on the basis of sustainable development is an important prerequisite for improving their ecological and economic efficiency. We believe that the solving of the mentioned task can be realized through the implementation of lean technology.

The lean production concept is based on the reduction of costs, which do not create value for consumer but make the final product more expensive. The relevance of the research is confirmed by the fact that in some countries about $20 \%$ of agricultural products don't reach the final consumer, although their production consumes a considerable amount of resources (including natural) $[1, \mathrm{p} .102]$. This situation requires the implementation of effective mechanisms of agricultural producers' activity efficiency increase in order to ensure their functioning on the basis of sustainable development.

\subsection{Literature review}

The importance of researches in the sphere of lean production has caused significant interest of scientists to the issue mentioned.

One of the most comprehensive approaches to the study of lean production concept implementation is provided by J. Liker [5]. The peculiarities and insights of the Toyota company experience at the lean production implementation are considered providing a complex and precise view of how the lean concept should be introduced in the Ukrainian practices. Another research

\footnotetext{
* Corresponding author: orlova_ekaterina@ukr.net
} 
which should be mentioned specifically is performed by J. P. Womack and D. T. Jones [17]. The complex characteristics of the main foundations of lean thinking concept is provided by the authors as well as the recommendations for practical implementation of lean concept.

O. Kobyliuh, H. Melnyk [4] mention that currently the lean concept is wide-spread in many countries with high level of economic and industrial development. The authors generalize the theoretical basis of the lean concept as well as practical aspects of its implementation.

H. Shportko and M. Vyshnevska [16] define the theoretical aspects of value stream mapping (VSM) as of the one of the efficient lean concept tools. The researchers provide the characteristics of the methodology of VSM implementation and consider the benefits provided by the tool.

The peculiarities of lean production concept implementation in the activity of agricultural enterprises are considered in the researches of D. Folians, D. Aidonis, N. Voulgarakis, D. Triantafylou [8] and V. Vostriakova [1]. The articles define the possibilities of lean tools implementation in activity of agricultural enterprises and emphasizes the role of VSM tool in the optimization of logistic activity costs formation processes.

Another tool which is similar to lean production concept according to its goals is so-called "green logistics". The "green logistics" concept is considered in the researches of I. Smyrnov [6], Paul R. Murphy, Richard F. Poist, Charles D. Braunschweig [14] and O. Kostiuk, M. Kaniuka [15]. The authors' [6; 14] definition of "green logistics' concept provides for more comprehensive understanding of lean production concept as these tools are deeply related from the point of view of their ecological impact. In the research of O. Kostiuk and M. Kaniuka [15] the main directions of logistic activity improvement on the basis of its "greening" are defined. V. Cruz Machado and S. Duarte [12] consider "green logistics" as well as lean supply chin among the supply chain paradigms which empower the enterprises to be more efficient in the logistic activity.

Practical cases are a powerful tool of definition of the road-map of lean production concept implementation, that causes the appropriate scientists' interest to this sphere $[2 ; 3 ; 9 ; 10 ; 11]$. Lean production concept as a theoretical background for the further research is reviewed in the B. Poksinska and D. Swartling research [2]. The authors define the opportunities and benefits provided by the lean concept implementation as an improvement programme through the introduction of a practical case of biopharmaceutical company. Bhuvaneshwari Alias Sunita Kulkarni and Anand H. Mishrikoti [3] state that lean production concept implementation forms a great impact on the functioning of small and medium-sized enterprises as it ensures waste reduction and costs optimization. The authors study several cases of lean concept implementation in various spheres of economic activity defining the peculiarities and outcomes of such practices. The Brazilian agricultural enterprises' experience in lean tools implementation is considered in the research of E. G. Satolo et al. [10]. The research provides a description of the most common lean concept tools and techniques as well as a practical view of their implementation in the activity of Brazilian agricultural business units. M. Melin and H. Barth [11] provide an extensive view on peculiarities of lean concept implementation in Swedish agricultural sector. The authors outline the essential elements and phases of lean thinking implementation, as well as note the role of appropriate governmental support programmes.

Acknowledging the valuable and significant contribution of the researchers in the sphere of lean production we should mention that the further development of ideas of lean production concept implementation in the activity of agricultural enterprises is relevant.

\subsection{Objective of research}

The purpose of the research is the acquaintance with conceptual foundations of lean production and substantiation of the possibility and expediency of application of the basics of this philosophy in agricultural enterprises activity in the context of ensuring their sustainable development.

\section{Results of the research}

The need for radical changes in the activities of Ukrainian agricultural enterprises is due, first of all, to the low quality of production and its high cost. Therefore, solving of these issues lies in the sphere of improving the efficiency of all business processes, both primary and support. According to foreign experience, the technical re-equipment of production, in the opinion of most farmers, will not ensure the proper level of all business processes efficiency and will not increase the efficiency of the latter, because it does not take into account the issues of personnel management, organization of logistics flows, financial flows management and the enterprise management as a whole. Thus, mastering the principles of lean production can be a significant competitive advantage in the current stage of management. The lean concept implementation in the activity of agricultural enterprises is capable to provide benefits for the economic entity and the society both, as it enables waste reduction (ecological impact) and costs decrease (economic impact).

\subsection{Lean production concept}

The concept of lean production is based on the idea of the business model of the enterprise, namely its part, which studies the business processes of the enterprise: primary, support and service, in terms of their role in creating added value, which is determined by the consumer value. So, the essence of lean production provides the identification and reduction of process costs, and sometimes elimination of those business 
processes that do not create added value but use a large amount of resources.

Lean concept is one of the most popular and efficient contemporary management tools as it provides not only increase of functioning efficiency, but also benefits to rational nature resources use.

The origin of lean concept comes from the case of Toyota company, particularly, the Toyota Production system, which was developed in the 1940s.

The lean production concept is defined as a system approach to production and other business processes organization, which involves continuous improvement, reduction of waste and satisfying the needs of consumers.

Lean production concept can be described both as a philosophy as well as a tool for production processes improvement [2].

Lean concept as a philosophy involves the formation of the consciousness of managers of different levels and directly employees of enterprises, which will be based on the principles of resource saving, rational resource use, waste reduction and recycling. Lean concept philosophy is focused on the continuous improvement and search of managerial and organizational approaches to the effective organization of business processes and the avoidance of unjustified losses and waste of resources.

In practical terms, lean concept includes a set of techniques and tools aimed at identifying "bottlenecks", reducing wastage and cost of resources in the implementation of various business processes.

Lean production concept tools and methods include a large number of techniques which can be applied in the economic entity activity. The most common tools of lean production concept include the following:

- 5S method - is aimed at reduction of waste of resources due to the improper organization;

- Kaizen - provides the opportunity to avoid waste in the production process;

- Kanban - benefits to avoiding wastage from overproduction and surpluses in stocks;

- Muda - is aimed at reduction of any activity and / or business processes which do not create added value for the product [3];

- Overall equipment effectiveness - ensures the flows tracking in order to avoid wastage in the production process;

- Value stream mapping - provides a graphical reflection of the production flow processes and enables identification of the "bottlenecks" of the process;

- Total productive maintenance - involves higher participation of employees in production and improvement processes that allows to avoid defects and decrease the duration of production cycle;

- Andon - provides the possibility for improving the communication during the production process, etc. [3].

The basis of "lean production" is called "muda". "Muda" means losses, unreasonable costs and any processes in the activity of the enterprise consuming resources without giving any value to the product or service [4, p. 45].
Main lean principles were defined by Jeffrey $\mathrm{K}$. Liker on the basis of Toyota experience and include the following [5]:

1. Base Your Management Decisions on a LongTerm Philosophy, Even at the Expense of Short-Term Financial Goals.

Adherence to this principle determines the priority of the strategic goals of the enterprise development in relation to its short-term perspective. Thus, obtaining short-term benefits can lead to lost opportunities in the strategic perspective, and reduce the level of success and competitiveness of the enterprise in the future.

2. Create Continuous Process Flow to Bring Problems to the Surface [5].

The relevant principle defines the importance of a systematic and continuous approaches to the organization of business processes in order to identify and eliminate "bottlenecks".

3. Use Pull Systems to Avoid Overproduction [5].

Provides an orientation of production processes on consumers' demand and a clear alignment of production volumes with consumer demand. The implementation of this principle will help to avoid over-costs due to the formation of unreasonable inventories.

4. Level Out the Workload (Heijunka) [5].

Compliance with this principle implies ensuring that the equipment is "aligned" to avoid downtime and peak loads, or the so-called "smoothing" of production.

5. Build a Culture of Stopping to Fix Problems, to Get Quality Right the First Time [5].

It is one of the principles that is formed at the managerial level and provides for the possibility of stopping production processes in case of problems in order to ensure a high level of quality of final products and avoid losses.

6. Standardized Tasks Are the Foundation for Continuous Improvement and Employee Empowerment [5].

The defined principle is based on the premise that the unification and standardization of works contribute to improving the quality of their performance, simplifying the procedural component for employees, and therefore provide a basis for improving production processes.

7. Use Visual Control So No Problems Are Hidden [5].

Provides the formation of a system for monitoring the quality of products and the organization of business processes in terms of timely identification and appropriate elimination of problems.

8. Use Only Reliable, Thoroughly Tested Technology That Serves Your People and Processes [5].

Involves the application of only proven techniques and technologies in the process of organization of production and other business processes, which provides for their adjustment and avoidance of accidental unjustified losses.

9. Grow Leaders Who Thoroughly Understand the Work, Live the Philosophy, and Teach It to Others [5].

Adherence to this principle determines the role of leadership and qualification of managers of different levels, who are subordinated to the corporate spirit and 
corporate culture, thus contributing to improving the efficiency of the enterprise.

10. Develop Exceptional People and Teams Who Follow Your Company's Philosophy [5].

This principle is in line with the previous one, because under the current conditions of increasing competition, it is human resources that are the source of the formation of significant competitive advantages. Forming a team of employees who will share the values of the organization is an important prerequisite for improving its efficiency.

11. Respect Your Extended Network of Partners and Suppliers by Challenging Them and Helping Them Improve [5].

The implementation of lean concept in the activity of the enterprise puts appropriate demands on its suppliers in terms of quality assurance of resources, timeliness of deliveries, etc. Forming long-term business relationships with reliable suppliers, sharing with them some of the best know-how and skills contributes to improving the quality of input resources.

12. Go and See for Yourself to Thoroughly Understand the Situation (Genchi Genbutsu) [5].

Provides the personal involvement of executives in the identification of problems, their resolution and improvement of processes.

13. Make Decisions Slowly by Consensus, Thoroughly Considering All Options; Implement Rapidly (Nemawashi) [5].

Adherence to this principle implies a comprehensive substantiation of management decisions, taking into account all possible alternatives and perspectives. At the same time, after a decision is made, it is advisable to implement it quickly, since the conditions and factors of both the external and internal environment are characterized by variability, which calls into question the efficiency of the implementation of a decision over a long period of time.

14. Become a Learning Organization Through Relentless Reflection (Hansei) and Continuous Improvement (Kaizen) [5].

Involves the necessity for continuous development and improvement of the organization in order to ensure its sustainable and competitive functioning.

According to the world experience, the implementation of lean production concept makes it possible to: reduce production costs; reduce order fulfillment cycle; reduce labor costs and labor losses; reduce stocks; increase production [6].

The essence of lean production is that all these types of costs are controlled by the company independently. If the price is dictated by the market through the consumer, then the rate of return will directly depend on the amount of costs incurred in production as the equation is the following:

$$
\text { Price }=\text { Costs }+ \text { Profit }
$$

Therefore, the company should take maximum measures to minimize all types of costs keeping the same quality of products. Taking into account the mentioned above, the concept of lean production is based on the following principles:

- to produce only the amount of products needed on the market;

- to abandon mass production;

- to minimize work in progress (unfinished production);

- to minimize stocks.

In view of the above, one can ask the following question: is it possible to introduce the basic principles of lean production in the agricultural sector, the peculiarity of which, along with the seasonality of production (crop harvesting is mostly collected once a year), is its mass production? The answer is that current conditions are so that the consumer is not ready to pay for products that are stored for a long time, are processed for storage with chemicals, and thus lose their quality and value. The consumer requires organic products (the feature of which is the impossibility of long-term storage). Meeting the mentioned consumer's needs contributes to the reaching of the following sustainable development goals: "Zero hunger", "Good health and well-being" and "Responsible consumption and production" [7].

\subsection{Lean production concept implementation cases}

Practical cases demonstrate the feasibility of implementation of lean technology into agricultural enterprises' activity. Thus, Greece's experience in the production of compound feeds once again shows the whole chain of lean production in action. Instead of drying corn up to $14 \%$ with energy consumption of $0,15 \mathrm{~kW} / \mathrm{t}$, storing it in an elevator and ventilating with special devices, spending additional energy on it, compound feed plants are organized. On these plants, corn is added to other feeds at a specified percentage weight.

There the corn is weighed, crushed, pelleted and packed or transported to the farm free of packing. Thus, energy consumption for compound feeds production is $85 \mathrm{~kW} / \mathrm{t}$, water consumption in the form of steam is 40$60 \mathrm{~kg} / \mathrm{t}$. Emissions are limited by gas / oil emissions when the water is heated to the steam state, solid waste in the form of dust is filtered into special bags, liquid emissions are absent $[1 ; 8 ; 9]$.

Another successful case of lean principles implementation can be observed at the example of Brazilian agricultural enterprises. Thus, Satolo Eduardo Guilherme et al. state that Brazilian agricultural enterprises (at the example of eight research units) utilize a number of lean production tools and techniques, among which are the following: autonomation, continuous flow, pull production, standardized work, kaizen, supply chain integration, uniform work load, total quality management, etc. [10]. The implementation of the tools mentioned above allows the research units to operate successfully, satisfying consumers' needs with simultaneous reduce of production costs.

The role and efficiency of lean concept implementation is also substantiated by some governmental programs. Thus, in 2010 the "Lean 
agriculture" governmental program was introduced in Sweden. The program provided learning of lean principles for agricultural producers, including traineeship, workshops and coaching in order to achieve the increase in performance efficiency. Approximately 100 farms have been involved to various types of activity within the program since it was introduced [11].

Thus, foreign experience in lean production concept implementation reflects its efficiency and effectiveness as well as forms the road-map for Ukrainian enterprises which are willing to apply the lean principles.

\subsection{Lean logistics}

Understanding the essence of the lean production concept makes it possible to implement it, if not for the whole process of agricultural production, then at least for such an important direction as lean logistics. Supply chain management will increase the efficiency of the production process as a whole. It should be noted that lean logistics should not be equated with "green supply chains". The latter focus on environmental protection through the maximum use or recycling (elimination) of waste. Lean logistics focuses on reducing costs and meeting consumer requests, while increasing the efficiency of agricultural production by increase of value added.

The implementation of lean logistics aims at optimizing the processes of the entire supply chain in order to simplify it, reduce losses and processes, which do not create value [12]. In other words, optimization of processes and acceleration of their execution will reduce the costs and increase the efficiency of the production system. The authors' lean concept in the agricultural supply chain is presented in Fig. 1.

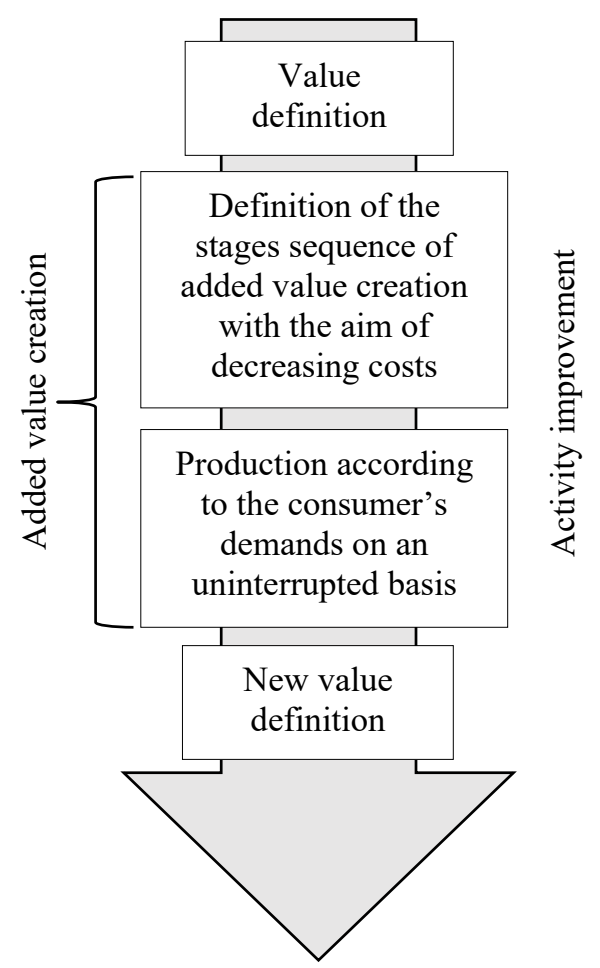

Fig. 1. Lean concept in the agricultural supply chain.
One of the Ukrainian agricultural enterprises that has introduced best practices with the use of lean tools such as the " $5 \mathrm{~S}$ " and the proposals of the employees for improvement of their work is the "Agro-Soyuz" holding. The results were a number of the following measures: the initiation by employees of 54 measures to balance the flow, 45 of which do not require investment; saving of 37 ths. UAH due to the systematization and redistribution of the furniture between the corporation divisions in the course of implementation of the principle "Removal of unnecessary"; receiving significant funds from scrap sales; a $41 \%$ increase in productivity [13].

"Green logistics", along with the concept of lean production, is important in agricultural production. According to P. Murphy, the term "green logistics" originated in the early 90 's of the XX century as a new method in logistics, which guides standard logistic requirements to the rationality, efficiency and speed of processing and movement of goods, and takes into account environmental measures [14]. "Green logistics" is understood as a tool for maintaining environmental security, which is an example of a socially beneficial and business-friendly symbiosis of ecology and economy and satisfies the terms of both preserving the natural environment and economic activity growth [6, p. 50].

Lean production in the context of the lean concept is a part of a large chain of "green logistics" that integrates financial, logistical and information flows while reducing costs throughout the value chain. Lean production provides the opportunity to gain a sustainable competitive advantage in the market by reducing material, energy, storing and transportation costs.

Among the global companies that adhere to the principles of "green logistics" are Toyota, Xerox, Johnson \& Johnson, Honda, Volkswagen, HewlettPackard, Casio, Sony and others. The effectiveness of "green logistics" principles can be demonstrated in practice by Sony, which in 2011 managed to reduce $\mathrm{CO} 2$ emissions by approximately $47 \%$ due to the packaging reduce. In 2011 also, Sony used about 31,000 return containers worldwide, thereby reducing the use of packaging materials and single-sided pallets by approximately 312 tones [15].

Due to the change in the thickness of the stretch film, its use decreased in volumes of up to two tons, which in turn contributed to the reduction of $\mathrm{CO} 2$ emissions by approximately five tons [15].

V. Vostriakova believes that the integration of lean and "green" logistics can create a hybrid agricultural and food supply chain that, along with cost reductions, will reduce environmental footprint and increase business efficiency and, as a consequence, product quality [1].

Under current conditions, this issue is relevant because, firstly, transportation does not add value to the product from the point of view of the final consumer, that is, it becomes a cost for the enterprise and, secondly, among many logistics systems (supply logistics, information logistics, sales logistics, production logistics, transport logistics) transport logistics is the most damaging to the natural environment.

With its abundant natural resources, Ukraine is one of the most polluted countries in the region. According 
to the environmental index, which is derived from 10 indicators, among which are water and air condition, biological diversity, environmental diseases, Ukraine ranked 102nd out of 132 countries [15].

The leading postulate of the lean concept, as noted, is that there are two types of costs: the first - the ones that create value for the consumer, all the others - bring only losses.

\subsection{Application of Value Stream Map tool}

Therefore, there are two types of costs in any production: costs that can either be reduced or avoided (overproduction, surpluses stocks, defects elimination, irrational internal logistics, unnecessary operations, downtime and equipment overhaul), and non-avoidable, and they do not create value for the consumer (labor costs).

The success of the lean concept in agricultural production can be ensured by the breakdown of the entire production process into a chain of operations, which create value added and which only generate costs. This can be done using the VSM (Value Stream Map) tool.

VSM is a visual representation of a step-by-step scenario for achieving the strategic goals of the enterprise; is a graphical diagram which shows the material and information flows required to deliver a product to the final consumer. The map allows to identify the "bottlenecks" of the flow, existing losses and develop a plan for costs optimization. This map gives the opportunity to:

- distinguish valuable and invaluable processes and determine what is most important to the consumer;

- reduce losses which are not paid for by the consumer;

- produce a map of the movement of products and information to the final consumer;

- model the process as a whole but not its individual parts [16].

Thus, it can be assumed that due to the VSM tool, the company will be able to analyze the entire production process, determine the stage at which value is added, and optimize costs that do not create value for the consumer, but increase the cost of the process. This tool helps to visualize agricultural business processes, from raw material delivery to final product, with key milestones, resources needed and time for implementation.

Designing a value stream map is one of the most important tools for building an organization in accordance with the principles of the lean production philosophy. Fig. 2 shows that this process is divided into two main stages of creating a VSM map.

Therefore, in the general form for agricultural enterprises the VSM card should have the following: defining a business process that creates value added and setting the time for its implementation; calculation of the required amount of energy resources (water, electricity, gas, oil, etc.) spent on production of a certain products volume; considering that the business process can be primary, support, service and managerial, the amount of energy resources is calculated to ensure the execution of each process per day; identifying processes that have the potential to increase resource efficiency and reduce costs, reduce environmental footprint, ensure the safety of the natural environment and the entire chain.

\begin{tabular}{l} 
1 stage \\
$\begin{array}{l}\text { Formation of a current condition map: } \\
\text { - analysis of the existing processes; } \\
\text { - identification of the losses sources }\end{array}$ \\
$\begin{array}{l}\text { Formation of a planned condition map: } \\
\text { - formation of a plan for elimination of } \\
\text { the losses sources; } \\
\text { - appointment of a project manager for } \\
\text { implementation of changes to a } \\
\text { particular flow; } \\
\text { - definition of the project key } \\
\text { indicators; } \\
\text { - definition of the terms of the project } \\
\text { implementation }\end{array}$ \\
\hline
\end{tabular}

Fig. 2. Stages of VSM formation.

The implementation of lean production principles will allow agricultural enterprises to find out cost-cutting reserves through optimization throughout the agricultural-food chain, to identify processes that do not create added value, but only burden the production process with unproductive costs. Thus, according to $\mathrm{M}$. Porter, the company will gain a competitive advantage by minimizing costs. This, in turn, will increase competitive position in the market, because the company will present its product in the form of value, not burdened with other costs. At the same time, the implementation of lean concept will help to reduce the anthropogenic burden on natural environment and to achieve the sustainable development goals.

Therefore, it can be confirmed that the implementation of the lean concept at agricultural enterprises is an element of ensuring their functioning on the basis of sustainable development, a means of improving environmental and economic efficiency.

\section{Conclusions}

Considering the environmental orientation that has developed in the global community at the present time, it is important for Ukrainian agricultural enterprises to combine the lean concept with "green logistics", which combine rational use of resources and environmental protection. Therefore, theoretical and practical aspects of finding of the intersection of points of interests and the possibilities of combining these two concepts require further development, in the context of the mechanism of implementation and expansion of tools for their application in our country. Lean production is the key to the sustainable development of agricultural enterprises. 


\section{References}

1. V. Vostriakova, Economy. Finances. Management: Topical Issues of Science and Practical Activity 9, 102 (2016)

2. B. Poksinska, D. Swartling, Total Quality Management \& Business Excellence 29, 996-1011 (2018). doi:10.1080/14783363.2018.1486539

3. B.A.S.Kulkarni, A.H. Mishrikoti, International Journal of Recent Technology and Engineering Special Issue 8, 959 (2019)

4. O. Kobyliuh, G. Melnyk, Visnyk Natsionalnoho Universytetu "Lvivska Politekhnika". Lohistyka 749, 43 (2012)

5. J.K. Liker, The Toyota Way: 14 Management Principles from the Worlds Greatest Manufacturer (McGraw-Hill, New York, 2004)

6. I. Smyrnov, Ukrainskyi Heohrafichnyi Zhurnal 2, 49 (2002)

7. United Nations, About the Sustainable Development Goals - United Nations Sustainable Development (n.d.),

https://www.un.org/sustainabledevelopment/sustaina ble-development-goals. Accessed 19 Feb 2020

8. D. Folians, D. Aidonis, N. Voulgarakis, D. Triantafylou, in I Logistics International Conference (2013), pp. 234-239

9. J. William Uhrig, D.E. Maier, Grain Quality Task Force 3 (1992)

10. E.G. Satolo, L.E.D.M. Hiraga, L.F. Zoccal, G.A. Goes, W.L. Lourenzani, P.H. Perozini, Gestão \& Produção 27 (2020). doi:10.1590/0104-530x325220

11. M. Melin, H. Barth, Production Planning \& Control 29, 845-855 2018). doi:10.1080/09537287.2018.1479784.

12. V. Cruz Machado, S. Duarte, in Proceedings of the 2010 International Conference on Industrial Engineering and Operations Management (2010), pp. 244-250

13. Agro-Soyuz Holding (2020), http://www.agrosoyuz.com. Accessed 19 Feb 2020

14. P.R. Murphy, R.F. Poist, C.D. Braunschweig, Journal of Business Logistics 17, 191 (1996)

15. O. Kostiuk, M. Kaniuka, in Marketynh i Lohistyka v Systemi Menedzhmentu: Conference Proceedings (2012), pp. 213-215

16. H. Shportko, M. Vyshnevska, Economy and Society 2, 376 (2016)

17. J. Womack, D. Jones, Berezhlivoe Proizvodstvo: Kak Izbavitsya Ot Poter $i$ Dobitsya Protsvetaniya Vashey Kompanii (Lean Thinking: Banish Waste and Create Wealth in Your Corporation) (Alpina Publisher, Moscow, 2013) 